\title{
The Role and Impacts of Growth Hormones in Maximizing Animal Production- A review
}

\author{
Duguma Dibbisa ${ }^{1, a, *}$, Ararsa Duguma ${ }^{2, b}$ \\ ${ }^{1}$ School of Biological Sciences and Biotechnology, Haramaya University, P. O. Box, 138 Dire Dawa, Ethiopia \\ ${ }^{2}$ College of Veterinary Medicine, Haramaya University, P.O. Box, 138 Dire Dawa, Ethiopia
}

*Corresponding author

A R T I C L E IN F O A B S T R A C T

Review Article

The purpose of the study is to examine the role and impacts of growth hormone in maximizing animal products. Growth hormones are biological stimulants that are found either naturally in the organism or synthetically manufactured. Phytoestrogens, phytoprogestrons and Phenolic compounds are hormones from plants. Drugs from of placenta and colostrums of cow`s contain progesterone, estrogene, gonadotropin, and prostaglandins hormones. Growth hormones have got popular applications in dairy, beef, feed improvement and Biopharmaceutical productions with the aim of producing valuable products: fat free meat (Porcine Somatotropin hormone in pigs), nutritionally and medicinally reach milk (Bovine Somatotropin hormone in cattle), palatable and disease and insect pest resistant forage crop production. They have got also contribution in maximizing livestock production by involving in adjusting animals' reproductive process such as oestrus synchronization and superovulation mainly during artificial insemination and embryo transfer. Controversially, these hormones have wide impacts on human being, animal welfare, environment and etc. Contamination of ground water by hormones that are found in the animals excreta will cause deleterious effects such as cancer, loss of fertility, and some imbalance of

minerals in the water and soil.

Animal production

Environmental contamination Growth hormone

Reproduction

Pharmaceutical production

chemduguma2013@gmail.com (iD) https://orcid.org/0000-0002-2534-6337

|b@ararsad@yahoo.com (iD https://orcid.org/0000-0003-1744-8381

(c) (1) ) This work is licensed under Creative Commons Attribution 4.0 International License

\section{Introduction}

Hormones are bioactive used to increase the feed efficiency, average daily gain, and carcass quality or milk production of animals. Genetics and nutrition are the two most important factors; however, growth promoters can improve the efficiency of animals. Growth hormones provide many functions for healthy body performance in enhancing animal production and productivities. They stimulate skeletal growth, protein anabolism (food conversion to living tissue) in many tissues that increase protein synthesis and decreased oxidation of proteins. Growth hormones also enhance availability of fat by stimulating breaking down of triglyceride and maintain blood glucose within normal range (National Academic Press, 2002).

There are five primary growth hormones in animal production: Somatotropins, Thyroxines, Glucocortoids, Androgens and Estrogens. Each species has its own somatotropin hormone that affects their growth. For instant, porcine somatotropin has been supplemented to increase leanness in hog carcasses, bovine somatotropin (BST) to increase milk production in dairy cows, Thyroxine to regulate metabolism of the cell, and glucocortoids to stimulate weight loss by mobilizing nutrients stored in the body. Androgens are produced by the testes in males (testosterone) and by the adrenal gland in females (Estrogens) both for muscle and bone growth, development of the secondary sexual characteristics and promote growth by stimulating the secretion of other growth hormone (CAERT, 2006).

There are six hormone growth promotants (HGPs) approved by the US Food and Drug Administration (FDA) for cattle industry to enhance beef production in 1956.These include three naturally occurring hormones: Oestradiol, Progesterone and Testosterone and three synthetically prepared hormones: Zeranol, Trenbolone, and Melengestrol. They are implanted or injected into cattle in various stages of maturity. The FDA however, does not permit injecting calves with these hormones. The 
male hormone testosterone and its synthetic equivalent trenbolone acetate, and the female hormone progesterone including three synthetic derivatives zeranol, 17 betaestradiol, and melengestrol acetate (MGA) are either implanted or injected into the cows. Melengestrol is a feed additive and is not injected, but added to the feedstock (Growth hormone in food, 2011).

Hormones play critical role in adjusting reproductive processes in animal production. These are stimulation or spermatogenesis, regular collection of semen and enriching its quality (for male); stimulation of ovogenesis, regulation of ovulation and the synchronisation of the estruses in the large groups of animals (Kistanova, 2003).

GHs are also part of artificially created environment in the laboratory, media, for in vitro animal cell or tissue culture which require a wide range of complex combination of nutrients and essential ingredients to support survival and proliferation or differentiation. Growth factors and hormones (Hydrocortisone, Insulin, Triodothyronine, and Thyroxine) are the essential nutrients externally supplemented in the medium. Genetically engineered poultry, swine, goats, cattle, and other livestock also are beginning to be used as generators of pharmaceutical and other products, potential sources for replacement organs for humans, and models for human disease (Coleman, 1996; Murray and Maga, 1999).

The genetically engineered hormones or growth promotants such as human (HST), bovine (BST) and procine (PST) somatotropin, interferon, lymphokines etc. are in the field-testing stage. They are ready to market for use in human and veterinary medicine to correct growth retardation and make hogs to grow faster with less fat and leaner production of dairy cattle (Kolodziej et al., 2004). Growth hormones are economically important for reproductive manipulations in livestock: genetic improvement, artificial insemination, embryo transfer and others. Contrarily, many researches output reveal also as they had got long lasting adverse impacts on dairy and beef productions, human health and on environments. Many hormones from recombinant bovine somatotropin milk and porcine somatotropin meat, steroid hormones can be retained to ground water through animal excreta. These cause ground water pollution as well as cancer, reproductive effects and endocrine disruption to human being (Harter et al., 2004). Nowadays, the world population has been constantly increasing and needs great attention of scientists to overcome the problem. No phenomenon this is made scientists to try improves the animal product maximization and its associated derivatives. It is very crucial to evaluate the role and impacts of growth hormone in animal production sectors. Therefore, the objective of this review paper was to investigate the role and impacts of growth hormone in maximizing animal production.

\section{The Growth Hormone}

Growth hormone $(\mathrm{GH})$ is a peptide hormone that stimulates growth, cell reproduction and regeneration in humans and other animals. Growth hormones are chemical substances produced naturally in different glands, which in minute quantities influence the performance of specialized groups of cells. Growth hormone is a 191-amino acid, single-chain polypeptide, synthesized, stored, and secreted by the somatotrophin cells within the lateral wings of the anterior pituitary gland into the hypophyseal portal venous blood (Wikipedia, the free encyclopedia). The secretion of $\mathrm{GH}$ is controlled by neurosecretory nuclei of the hypothalamus (Growth hormone-releasing hormone/somatocrinin and growth hormone-inhibiting hormone/somatostatin). However, although the balance of these stimulating and inhibiting peptides determines $\mathrm{GH}$ release, this balance is affected by many physiological stimulators and inhibitors of GH secretion (e.g., Free fatty acids) (Lindsley et al., 2009).

Inhibitors of $\mathrm{GH}$ secretion include somatostatin from the periventricular nucleus, circulating concentrations of GH and IGF-1 (negative feedback on the pituitary and hypothalamus), hyperglycemia, glucocorticoids and dihydrotestosterone (Lindsley et al., 2009; Pandey et al., 1999). In addition to control by endogenous and stimulus processes, a number of foreign compounds (xenobiotics such as drugs and endocrine disruptors) are known to influence GH secretion and function (Scarth, 2006).

Growth Hormones act by interacting with a specific receptor on the surface of cells. For example: increase in height in animals is the most widely known effect of $\mathrm{GH}$ is stimulated by at least two mechanisms. Initially it is because of fat-insolubility of polypeptide hormones that they cannot penetrate sarcolemma. Thus, GH exerts some of its effects by binding to receptors on target cells, where it activates the MAPK/ERK pathway (Binder et al., 2007). Through by this mechanism growth hormone directly stimulates division and multiplication of chondrocytes cartilage. Additionally, growth hormone stimulate through the JAK-STAT signaling pathway, the production of insulin-like growth factor 1 (IGF-1, formerly known as somatomedin), a hormone homologous to proinsulin (http://www.lib.mcg.edu/edu/eshuphysio/program/section 5/5ch2/s5ch2_19.htm).

Liver is a major target organ of $\mathrm{GH}$ for this process and is the principal site of IGF-1 production. IGF-1 has growthstimulating effects on a wide variety of tissues. ImmunoglobulinF-1 can be generated within target tissues, making it what appear to be both an endocrine and an autocrine hormone. IGF-1 also has stimulatory effects on osteoblast and chondrocyte activity to promote bone growth.

\section{Sources of Growth Hormones Used in livestock production}

The use of synthetic hormones has numerous negative consequences: interruption of natural hormones status, change in quality of products due to accumulation of hormonal drugs in meat and milk of animals (Kistanova, 2003). These problems forced to use natural sources of hormones for success of reproductive processes from plant and animal products which have the ability to stimulate the reproductive functions in animals.

The popular hormones of an animal origin are drugs from of placenta of cows, cow`s colostrums and colostrums drugs (Shubbina, 1995; Habbibulin, 1998). They contain a complex of natural hormones: progesterone, estrogene, gonadotropin, prostaglandins, and also vitamins, trace substances and other biologically active materials. All these components enhance functions of a uterus and 
ovaries by rendering a promoting effect on nervous system; activate immune system and all physiological processes of the metabolism. They also promote fast regeneration of the broken functions by diseases of the reproductive organs and reduce twice the dose of expensive synthetic drugs by their joint use (Shubina et al., 1996).

Plants also contain hormones playing great role in the regulation of the reproductive processes of animals. More than 300 plants and plant products contain phytoestrogens and phytoestrogens and phytoprogestrons (Thigpen et al., 1999). Phenolic compounds (coumarines, isoflavones, and steroids) whose chemical nature and action are similar to animal steroids hormones are the most important active substance of plants (Palfii and Malik, 1998). Example drugs from pumpkin stimulate physiological activity enhance reproduction functions of animals. Phytoestrogens influence positively all physiological functions of an organism rendering the stimulant, the estrogenic effect on the central nervous system, these compounds induce the estrus, stimulate the biosynthesis processes in tissues of a reproductive organs of female animals (Thigpen et al., 1999). Reduce risk of originating the cancer diseases of reproductive organs (Le bail et al., 2000). In medicine phytoestrogenic drugs are used as alternatives to classical hormones therapy (Huber, 2000). It is said that the phytoestrogens can protect against breast cancer.

Phytoestrogens and phytoprogestrons extracts with optimum doses can be used in animal breeding practices for stimulation of reproductive functions of female animals at the different stages of a sexual development. Other stimulants from plants also can be applied for the improvement of sperm quality by conservation in vitro (Kistanova, 2003). For example: the in vitro investigation of ram and bull sperm reveals that plant hormone gibberellins A activates the motility and live ability of spermatozoids in fresh and stored ram sperm as well as in post-thaw bull sperm bull sperm in vitro whose effectiveness depends on the concentration of gibberellins A (Kistanova et al., 2001; Kolev et al., 2000). Since it is one way of receiving economically clean products, the use natural stimulants in reproduction of domestic animals will develop tremendously.

\section{Applications of Growth Hormones in Dairy Farm}

Bovine somatotropin (BST) is a hormone naturally secreted by the pituitary glands of cows. Traces of BST are found in the milk secreted by the hormone injected animal. BST is also known as BGH, or bovine growth hormone. It interacts with other hormones in cows' bodies to control the amount of milk they produce (CAERT, 2006).

The use of bovine somatotropin (BST) to increase milk yield from dairy cows has had a long-chickened history and is the subject of trade disputes a around the world. In 1993 even if Europeans' banned the use of BST dairy cattle even for experimental studies, FDA approved BST for use in U.S. because testing had revealed no concerns regarding consumer safety (Juskevich and Guyer, 1990).

The BST, which is almost indistinguishable in sequence from the natural hormone, is present in low concentrations in milk and has no biologic activity in humans. The level of IGF- 1, the hormone induced by BST, is somewhat elevated within the "physiologic range" for cows through genetic engineering (Burrin, 1997). Lactating cows are injected with $\mathrm{rBGH}$, to increase their lactation period and even to determine stages of oestrous cycle through bovine milk progesterone test. This hormone interacts with other hormones in cows' bodies to increase the amount of milk they produce (CAERT, 2006). The greatest concerns about BST are probably in the area of animal welfare. High-yield milking cows show a greater incidence of mastitis than lower-producing cows, but studies have shown that mastitis is not exacerbated by BST administration. Another concern which is a practical one for the dairy industry is a recent trend to breed heifers only once and then to sustain milk production for as long as 600 days by using BST. Lengthening lactation via BST in second calf and older cows is a larger contributor to having fewer calves per lifetime in the herd than first-calf heifers. The result has been a shortage of replacement heifers for producers, since only one calf is born during the milking life of the animal (Harlow, 2002).

\section{Applications of Growth Hormones in Beef Animals}

There are three synthetic hormones approved by the U.S. Food and Drug Administration (U.S. FDA) for cattle and sheep for meat production: the estrogenic compound zeranol, the anabolic steroid trenbolone acetate (TBA), and the progestin melengestrol acetate (MGA). In the United States synthetic hormones are often administered as implants and in combination with each other or with natural hormones (17- $\beta$ estradiol, progesterone, and testosterone) at least once in their lifetime and many cattle receive more than one implant (USDA, 2000).

There are six hormone growth promotants (HGPs) approved by the US Food and Drug Administration (FDA) for cattle industry to enhance beef production both in quantity and quality. These include three naturally occurring hormones: Oestradiol, Progesterone and Testosterone and three synthetically prepared hormones: Zeranol, Trenbolone, and Melengestrol (CAERT, 2006).

Beef producers inject their cattle with growth hormones because they improve meat quality by increasing the development of lean meat and decreasing fat content; Increase feed efficiency, thereby allowing more growth with less feed; Reduce costs for producers thereby reducing the price of meat and meat products for consumers (National Academic Press, 2002).

Steroid hormones are used to increase the rate of weight gain and to reduce accumulation of fat deposits of in young heifers and steers. The steroids are administered by slow release from a plastic implant embedded beneath the skin of the ear, circulating levels of the hormone in the bloodstream (Yajima et al., 2002). The mainly used hormones are Zeranol, a naturally occurring fungal metabolite (zearalenone) with estrogenic action; estradiol, progesterone, and testosterone, or formulations of these steroids and trenbolone (Doyle, 2000; Meyer et al., 2002). The adverse effects of these hormones on human being made it to be banned from use in the poultry and beef industry. However, their presence in small amounts from consumed meat derived from treated cattle and numerous scientific studies indicate that these residues exist at low concentrations that they pose little risk to consumers 
(European Commission, Scientific Committee on Animal Health and Animal Welfare, 1999).

Geological Survey has recently documented the presence of hormones in a number of streams and rivers (Kolpin, 2002). Despite the scientific evidence for safety that, the European Union implemented a ban on U.S. beef imports, valued at over \$100 million per year in 1989 (Avery and Avery, 2007). Hormones pose any sort of environmental threat through their leaching into soil and water. For example, studies have shown that a commonly used androgenic growth promoter trenbolone has been found in groundwater near cattle feedlots, and that this growth promotor has androgenic effects (Bettina et al., 2001).

\section{Applications of Growth Hormones in Livestock Feeds Production}

The day to day decreases in yield, nutritional content, palatability and genetic deterioration of forage crops due to various biotic and a biotic factor such as stresses, diseases and insect pest, salinity and other factors is a current concern in animal production. The use of modern biotechnology tools such as plant tissue culture for in vitro regeneration can solve these problems. Tissue culture technology is one of those means where growth hormones are commonly incorporated as one component of the growth medium.

Accordingly, the in vitro regeneration of plantlets needs extra addition of growth hormones such as auxins, cytokinins and gibberellins to the growth medium the depending on the plant's totipotency (Gana, 2010). Reforestation of endangered forage crops through germplasm conservation and manipulation through germinated embryos in conjunction with specifically controlled in vitro condition and exogenously application of plant growth regulators are also other options which completely depend on growth hormones (Jaime and Texixeir, 2003; Amoo and Ayisire, 2005).

Growth hormone had been used as a feed widely in the beef cattle industry. Australia had been implanted cattle with around half of both grain-fed (feedlot) and pasturefed. Grain feeding cattle in feedlots in combination with the use of hormone growth promotants (HGP) is considered as efficient way of producing beef of consistent taste, tenderness and colour to suit customer demand (Hunter, 2010).

Feed additives are substances added to animals` feed to provide a specific nutrient needed or increase an animal's resistance to diseases by influencing the activity of ruminant microbes. These are antibiotics: boost immune systems, beta agonists: increase protein synthesis and decrease fat production (in swine production) and Melengestrol acetate (MGA): suppress oestrus (heifers for harvest).

\section{Applications of Growth Hormones in Reproductive Processes of Livestock}

Hormones play critical role in adjusting reproductive processes in animal production. These are stimulation or spermatogenesis, regular collection of semen and enriching its quality (for male); stimulation of ovogenesis, regulation of ovulation and the synchronisation of the estruses in the large groups of animals (Kistanova, 2003).

Earlier evidences indicate that embryo recovery and transfer provide the opportunity for a particularly animal to parent many offspring in her lifetime than would be otherwise possible (Seidel, 1984). The embryos also can be frozen and then either stored or transported before they are used to initiate a pregnancy. It is a relatively common technology and has been used to produce around 40,000 to 50,000 thousand beef calves every year (National Association of Animal Breeders, 1999). The approach is to induce, by using hormones, the maturation and release of more than a single egg from the ovaries (Driancourt, 2001). Then, the animal usually is inseminated with semen from an equally select bull, and the embryos are collected and transferred individually, or in pairs, to the reproductive tract of less valuable cows, which carry the calf to term.

Artificial insemination (AI) is another reproductive process which is a popular and widely used in animal breeding. AI is the transfer of semen collected from artificially ejaculated male to a recipient female after female estrous cycles are regulated with hormone injections (Madan, 2002). Artificial insemination for best semen quality evaluation by semen bank evaluates regarding the processing, storage and thawing of semen procedures are inadequate (Sansone et al., 2000). But several modifications of the techniques have been suggested to increase the conception rate. Oestrus synchronization and conception rate improvement with different stimulants and use of Gonadotropin-releasing hormones $(\mathrm{GnRH})$ followed seven day later by prostaglandin F2 $\alpha(\mathrm{GnRH})$ (Schmitt et al., 1996). An injection of GnRH on day 0, PGF2 $\alpha$ on day 7 and on day 9 is used for synchronization of ovulation and permitting timed insemination.

Embryo transfer (ET) is one of the major reproductive technologies that can facilitate genetic improvement in cattle. Unfortunately, commercial ET programmes are limited by the high variability in the ovarian follicular response to gonadotropin stimulation (Madan, 2002). The use of recombinant bovine somatotropin (rBST) in dairy cows increases both milk yield and production efficiency and decreases animal fat. Also A porcine somatotropin has been developed that increases muscle growth and reduces body-fat deposition, resulting in pigs that are leaner and of greater market value (National Academic Press, 2002).

\section{Impacts of Recombinant Bovine Growth Hormones in Milk Production}

Animals treated with the hormone are subjected to tremendous stress. For about 12 weeks after calving, a cow produces milk. During this process, the cow loses weight, is infertile and is more susceptible to diseases. As the milk output diminishes, the cow's body begins to recover. By injecting a cow with $\mathrm{rBGH}$, a farmer extends this milching period by eight to 12 weeks. Even as these hormone injections substantially increase the cow's milk output, they also make her more susceptible to disease.

The US Food and Drugs Administration (FDA) requires Monsanto to state on the labels of every shipment of Posilac (the name of the rBGH hormone), the 21 health problems associated with the use of the hormone. These include cystic ovaries, uterine disorders, decrease in 
gestation length and birth weight of calves, increased twinning rates and retained placenta.

Hormone injected cows are susceptible to mastitis inflammation of the udder. Since a cow with mastitis produces milk with pus in it, something which is not acceptable to dairies (dairies check milk for high somatic cell count i.e. high proportion of pus), farmers give antibiotics to treat the ailing cows (Growth Hormones in Food, 2011).

\section{Impacts of Growth Hormone in Beef Production}

There are serious concerns about health and welfare of animals in factory farms and those that are injected with growth hormones. Organizations such as the None Profit Animal Welfare Institute, supports family farms and the humane treatment of animals and periodically check on them. The place of injection and the gap between two points where the hormone injections have been given are very important. Places such as below the ear have significant muscle movement, causing the lesion to enlarge and the medication and irritation to spread beyond the site of original injection (Growth Hormones in Food, 2011).

The ultimate unidirectional focus of research on production or performance characteristics had brought animal welfare effects of growth hormones. Feedlots themselves may pose a risk to the welfare of cattle. A study suggested that cattle with just an oestrogen implant are adversely affected by hot climatic conditions and managing heat load in feedlot cattle is crucial to animal's welfare (Mader et al., 2005). In beef cattle production the use of hormone growth promotants can causes uncommon occurrence of chronic stress condition as signs of poor welfare (Marin et al., 2008). This is occurred when hormonal implants interact with the animal's natural hormones.

Growth hormones in beef exposed Americans at risk for infertility. A recent study found that women who routinely ate beef were far more likely to give birth to boys who grow up to have lower-than-normal sperm counts. Hormone residues in beef have been implicated in the early onset of puberty in girls, which could put them at greater risk of developing breast and other forms of cancer (Growth Hormones in Food, 2011).

\section{Impacts of Synthetic Growth Hormones on Environmental}

Significant amounts of synthetic and natural hormones and their metabolites are excreted in animal waste (Kolok and Sellin, 2008). Beef cattle wastes are strongly androgenic (Durhan et al., 2006). Synthetic hormones excreted by animals are present in manure applied as fertilizer and in feedlot retention ponds, and from there they may be retained in soil or transported to ground and surface water (Khan et al., 2008a; Lee et al., 2008b) calculated the number of beef cattle implanted with estrogens and androgens or progesterone, and the percent of applied hormone that reach the environment via cattle excrement. These numbers represent an increase in estrogens and androgens or progesterone over natural elimination rates. Livestock farming is thought to be the major source of steroid hormones found in regional groundwater (Davis et al., 2006) and external surface water.

Humans are potentially exposed to the synthetic hormones by consumption of commercial meat products and from environmental exposures related to animal waste (National Residue Program, 2006). Human exposure to both the synthetic and natural hormones causes cancer, reproductive effects, and other endocrine disruption outcomes. Estrogen is carcinogenic, anabolic steroids are reproductive toxicants and trenbolon is anabolic steroid. TBA, zeranol, and MGA cross the placenta and are detectable in fetal tissues in rabbits (Lange et al., 2002a).

Some evidences showed that xenobiotic growth promoters and their metabolites are thought to be genotoxic (Metzler and Feiffer, 2001). Veterinary use of hormones causes postmenopausal women, and pre-pubertal children, leaving them more vulnerable to the effects of exogenous hormone exposure (UK VPC, 2006).

\section{Conclusion}

Growth hormones from different sources can play great role in maximizing livestock production by being physiological component of many processes. Almost all animal production improvement ways are completely dependent on growth hormones. For better yield and quality in terms of contents in livestock products, hormones can be incorporated unlikely from the normal activity through different reproductive manipulations and engineered genetically with foreign genes. Hormones can be implanted for oestrus synchronization and super ovulation during artificial insemination and embryo culture (rBST and PST hormones for milk and fat free meat production in cattle and pigs respectively). However, these growth hormones have imposed deleterious impact on human health (cancer, decrease in fertility), ground water contamination, danger on animal welfare and others. So, unless following natural procedure (organic) for improvement of livestock production and search for alternative solutions, the use of growth hormones especially in genetically engineered organisms is sustainable and will be at risk stage. From this short review it was concluded that growth hormone plays a crucial role in maximizing the animal products. Therefore, it was suggested that using growth hormone in livestock production is a wise technology in nowadays world.

\section{References}

Amoo SO, Ayisire, BE. 2005. Induction of callus and somatic embryogenesis from cotyledon explants of Parkia biglobosa. Africa Journal of Biotechnology, 4: 548-553.

Avery A, Avery D. 2007. The Environmental Safety and Benefits of Phar-maceutical Technologies in Beef Production. Center for Global Food Issues, Churchill, VA, and http://www.cgfi.org/pdfs/nofollow/beef-eco-benefitspaper.pdf.

Bettina S, Andreas D, Karsten M, Heinrich HD. Meyer. 2001. The Fate of Trenbolone Acetate and Melen.gestrol Acetate after Application as Growth Promoters in Cattle. Environmental Studies. Environmental Health Perspectives, 109(11): 1145-51.

Binder GN, Wittekindt, Ranke MB. 2007. Noonan Syndrome: Genetics and Responsiveness to Growth Hormone Therapy, Horm Res, 67: 45-49. 
Burrin. 1997. Book Review: Membrane Protein Models. Centre for Agriculture and Environmental Research (CAERT). 2006. Growth promoters in animal production.

Coleman A. 1996. Production of proteins in the milk of transgenic livestock: problems, solutions and success. Am J Clin Nutr, 63: 39-45.

Cottom, Wright GA, Carver D. 1991. High level expression of active human alpha-1-antitrypsin in the milk of transgenic sheep. Biotechnology, 9: 830-834.

Davis RK, Orndorff HA, Peterson EW. 2000. 17 $\beta$-estradiol as an indicator of animal waste contamination in mantled karst aquifers. J Environ Qual, 29: 826-834.

Doyle E. 2000. Human Safety of Hormone Implants Used to Promote Growth in Cattle. A Review of the Scientific Literature, FRI Briefings Food Research Institute, 1-24.

Driancourt MA. 2001. Regulation of ovarian follicular dynamics in farm animals. Implications for manipulation of reproduction. Theriogenology sciences direct, 56 (6): 1211-1239.

Durhan EJ, Lambright CS, Makynen EA, Lazorchak J, Jartig PC, Wilson VS, Gray LE, Ankley GT. 2006. Identification of metabolites of trenbolone acetate in androgenic runoff from a beef feedlot. Environ HealthPerspect, 114(11): 65-68

European Commission, Scientific Committee on Animal Health and Animal Welfare. 1999. Report of the (European Union) Scientific Committee on Animal Health and Animal Welfare on Aspects of the Use of Bovine Somatotropin.

Seidel GE.1984. Applications of Embryo Transfer and Related Technologies to Cattle. J Dairy Sci, 67: 2786-2796.

Gana AS. 2010. The role of synthetic growth hormones in crop multiplication and improvement. African Journal of Biotechnology, 10:10330-10334.

Growth Hormones in Food. 2011. $20^{\text {th }}$ November.

Habbibulin RI. 1998. Colostrum extracts for synchronization of heifer estrus. Zootechnia. 41-47.

Harlow S. 2002. Where have all the heifers gone? Dairy Business Communications. Available online at http://www.dairybusiness.com/northeast/Feb02/Feb02NED Bp16.htm.

Houdebine LM. 2000. Transgenic animal bioreactors. Transgenic Res, 9:305-320.http://www.lib.mcg.edu/edu/eshuphysio/ program/section $5 / 5 \mathrm{ch} 2 / \mathrm{s} 5 \mathrm{ch} 2$ _19.htm.

Huber J.2000. Phytoestrogens and Serms, alternatives to classical hormones therapy. Ther.Umsch, 651-654.

Hunter RA. 2010. Hormonal growth promotant use in the Australian beef industry, Beef Production Science, 50: 637-659

Jaime A, Texixeir DS. 2003. Thin cell layer technology forage crop micropropagation and Biotechnology. Africa Journal of Biotechnology, 2: 683-691.

Juskevich JC, Guyer CG. 1990. Bovine growth hormone: human food safety evaluation Sciences, 249 (4971): 875-884.

Khan SJ, Roser DJ, Davies CM, Peters GM, Stuetz RM, Tucker R, Ashbolt N. 2008a. Chemical contaminants in feedlot wastes: Concentrations, effects and attenuation. Environment International, 34: 839-859.

Kistanova E, Kolev A, Karcheva V, Hrjanin N. 2001. The study of pant hormones gibberlin A on motility and livability of ram and bull spermatozoids. Animal sciences, 90-93.

Kistanova E. 2003. The use of biologically active substances from plant and animals products for the stimulation of the reproduction in domestic animals. Journal of biotechnology in animal husbandry, 19: 1-92.

Kolev A, Hrjanin N, Kistanova E, Karcheva V. 2000. Effect of plant hormone gibberlin $\mathrm{A}$ on some quality parameters of fresh and stored ram`s sperm. $6^{\text {th }}$ Intern. Symposium on animal reproduction, Ohrid, Proceed, 68.

Kolodziej EP, Harter T, Sedlak DL. 2004. Dairy wastewater, aquaculture, and spawning fish as sources of steroid hormones in the aquatic environment. Environ Sci Technol, 38: 6377-6384.
Kolok AS, Sellin K. 2008. The environmental impact of growthpromoting compounds employed by the United States beef cattle industry: history, current knowledge, and future directions. Reviews of Environmental Contamination and Toxicology, 195: 1-30.

Kolpin DW. 2002. Pharmaceuticals, Hormones, and Other Organic Wastewater Contaminants in U.S. Streams, 19992000: National Contaminants in U.S. Streams, 1999-2000: A National Reconnaissance, Environ. Sci. Technol, 36: 12021211

Lange IG, Daxenberger A, Meyer HHD, Meyts E, Skakkebaek NE, Veeramachaneni DNR.2002a. Quantitative assessment of foetal exposure to trenbolone acetate, zeranol and melengestrol acetate, following maternal dosing in rabbits. Xenobiotica, 32:8; 641-651.

Le bail JC, Champavier Y, Chulia AJ, Habrioux G. 2000. Effect of phytoestrogens on aromatase, 3 beta and 17betahydroxysteroid dehydrogenase activities and human breast cancer cells. Life Science, 66: 81-91.

Lee LS, Sassman SA, Khan B. 2008b. Degradation of synthetic androgens $17 \alpha$ - and $17 \beta$-trenbolone and trendione in agricultural soils. Envrion Sci Technol, 42: 3570-3574.

Lindsley N, Bartholomew, Edwin F, Martini, Frederic, Judi. 2009. Fundamentals of anatomy \& physiology. Upper Saddle River, NJ: Pearson Education Inc, 616-617.

Madan ML. 2002. Biotechnologies in animal reproduction. Key note address at international conference on animal biotechnology, Tamilnadu Vaterinary and Animal Science University, Chennai.

Mader TL, Gaughan JB, Kreikemeier WM. 2005. Hormonal growth promotant effects on grain-fed cattle under different environments. International Journal of Biometeorology, 49: 396-402.

Marin, Pozza AG, Gottardo F. 2008. Administration of dexamethasone per os in finishing bulls. II. Effects on blood parameters used as indicators of animal welfare. Animal, 2: 1080-1086.

Metzler M, feiffer EP. 2001. Genotoxic potential of xenobiotic growth promoters and their metabolites. Acta Pathologica, Microbiologica Immunologica Scandinavica, 109: 89-95.

Meyer HHD, Lange IG, Daxenberger A, Schiffer B, Witters H, Ibarreta D. 2002. Sex hormones originating from different livestock production systems: fate and potential disrupting activity in the environment. Anal Chim Acta, 473: 27-37.

Murray JD, Maga EA.1999. Changing the composition and properties of milk. In: Murray JD, Anderson GB, Oberbauer AM, McGloughlin MM (eds.). Transgenic Animals in Agriculture. Wallingham, UK: CAB International, 304.

NAAB (National Association of Animal Breeders). 1999. Breakthroughs in biotechnology: research equips producers with an array of genetic improvement tools. In Electronic Resource Guide, Available online at www.naabcss.org/education/biotech/html.

National Research Council 2002. Animal Biotechnology. National Academic Press. 2002. http://www.nap.edu/catalog/ 10418. html.pdf.

National Research Council. 2002. Animal Biotechnology. National Academic Press. 2002; (http://www.nap.edu/catalog/ 10418.htm).

National Residue Program (NRP). 2006. USDA Food Safety and Inspection Service, Office of Public Health Science. Dec, 2007.

Palfii UV, Malik OG. 1998. The problem of secondary compounds in plant and animal industries. Agricultural biology, 10-14.

Pandey UK, Birthal PS, Kumar A, Ravi Shankar A. 1999. Sources of growth in the livestock sector. National Centre for Agricultural Economics and Policy Research, Policy paper No. 9New Delhi, PP58. 
Sansone G, Nastri MJF, Fabbrocini A. 2000. Storage of buffalo (Bubalus bubalis) semen. Anim. Reprod. Sci, 62: 55-76.

Scarth JP. 2006. Modulation of the growth hormone-insulin-like growth factor (GH-IGF) axis by pharmaceutical, nutraceutical and environmental xenobiotics: an emerging role for xenobiotic-metabolizing enzymes and the transcription factors regulating their expression. A review". Xenobiotica, 36: 119-218.

Schmitt EJ, Diaz PT, Drost M, Thatcher WW. 1996. Use of a gonadotropin-releasing hormone agonist or human chorionic gonadotropin for timed insemination in cattle. J. Anim. Sci, 1084-1091.

Shubbina LA. 1995. The methods of improvement of the fertility of high productive cows, 240.

Shubina LA, Shubbin AA, Antovova FK, Kudrjavceva VN, Novikova VA. 1996. Preparation of high productive cows to an insemination.-Zootehnia, 26-29.

Speksnijder G, Baugh LR, Morris JA, Ivarie R, Harvey AJ. 2002. Expression of exogenous protein in the egg white of transgenic chickens. Nat. Biotechnol, 20: 96-399.
Sudharsan S. 2006. Biotechnology in Animal Production, technical digest, issue number, $9, \mathrm{P} 4$.

Thigpen J.E, Setchell KD, Ahlmark KB, Locklear J, Walmer T, Spahr T, Caviness GF, Goeiz MF, Haseman JK, Newbold RR, Forsythe DB. 1999. Phytoestrogen content of purified, poen and closed formula laboratory animal diets. Lab Anim Sci, 49(5):530-6.

United Kingdom Veterinary Products Committee (UK VPC). 2006. Report of the Veterinary Products Committee. Risks associated with the use of hormonal substances in foodproducing animals.

United States Department of Agriculture (USDA). 2000. Part I: Baseline Reference of Feedlot Management Practices, USDA. APHIS: VS, CEAH, National Animal Health Monitoring System.

Yajima S, Lammers MM, D'Souza U, Qin ZH, Lee SH. 1999. Mouradian Regulation of striatal dopamine receptors by estrogen Synapse, 34: 222-227. 